\title{
PATTERNS OF TOOTH CROWN WEAR IN DRYOMYS NITEDULA (MAMMALIA, RODENTIA): AGE-RELATED VARIATION IN THE LIGHT OF ANNUAL CYCLE SPECIFICS BASED ON MUSEUM COLLECTIONS
}

\author{
I. Zagorodniuk*, Z. Barkaszi, M. Korobchenko \\ National Museum of Natural History, National Academy of Sciences of Ukraine; \\ Bohdan Khmelnytsky St., 15, Kyiv, 01030 Ukraine \\ E-mail: igor.zagorodniuk@gmail.com \\ ${ }^{*}$ Corresponding author \\ I. Zagorodniuk (https://orcid.org/0000-0002-0523-133X) \\ Z. Barkaszi (https://orcid.org/0000-0003-3155-6362) \\ M. Korobchenko (https://orcid.org/0000-0002-1063-482X)
}

Patterns of Tooth Crown Wear in Dryomys nitedula (Mammalia, Rodentia): Age-Related Variation in the Light of Annual Cycle Specifics Based on Museum Collections. Zagorodniuk, I., Barkaszi, Z., Korobchenko, M. - The specifics of age-related variation of tooth crown wear in Dryomys nitedula from Ukraine were analysed. The study is based on a morphological sample of 101 specimens (studyskins and skulls), which have been amassed in zoological museums of Ukraine since their establishment. Results suggest that patterns of enamel wear are closely related to the specifics of the species' annual cycle, in particular to periods of activity and hibernation. It was revealed that the longest period of the species' activity lasts 5.3 months, and, respectively, the forest dormouse hibernates during not less than 6.5 months. Based on the level of enamel wear, an improved method of age group determination was developed and applied successfully. Six age groups were selected that largely differ by the number of respective specimens with a clearly expressed decrease from the group SAD1 to group SEN. Similarly, there is also a clear decrease in the duration of active phase of annual cycle among subsequent age groups: in groups JUV to AD1, the active period lasts 6 months, while animals of age groups AD2 to SEN are active only for 1 to 4 months. The period of recorded activity decreases with the age determined by the level of tooth crown wear. Morphometric data presented suggest that definitive means of morphometric characters are already formed until the first wintering. The absence of young specimens in the samples and the sharp decrease in the number of adults (age groups AD2 and SEN) are discussed as well. Most of the species' records are from the forest steppe zone of Ukraine and the portion of the forest dormouse in forest steppe communities seems to be extremely low (its catches on trap-lines are rather occasional). Key words: dormouse, age groups, tooth crown wear, museum collections. 


\section{Introduction}

A large number of small mammal species are characterised by a short life cycle that often lasts only a single season or year. Among them are species that, despite their small size, have a relatively long and complex life cycle, such as hibernating or migrating species of bats, birch mice, dormice, ground squirrels, and hamsters (Kalabukhov, 1956; Godlevska \& Gol'din, 2014). In those species the start of breeding period and the general course of the life cycle are related rather to seasonal rhythms, particularly to wintering, hence processes of growth and development are periodic. In the fauna of Ukraine, dormice are a typical example of such mammals (Kalabukhov, 1956).

In Ukraine, four species of dormice occur (Bezrodny, 1991; Zagorodniuk \& Emelyanov, 2012), among which the forest dormouse, Dryomys nitedula, is common not only in the forest but also in the steppe zone, where it enters through bairak forests ${ }^{1}$, forest belts and other artificial ecological networks. The species is one of the most common rodents in Europe (Kryštufek \& Vohralik, 1994). However, data on its ecology and seasonal activity in Ukraine are scarce and reported briefly only in general fauna descriptions (e. g., in Sokur, 1960) or analyses of community structures (e. g., Zagorodniuk, 2008). Few publications are concerned with the ecology of the forest dormouse in the region (Zaitseva \& Sagaidak, 2011), partly because researchers paid more attention to other dormice species, especially to the common dormouse, Muscardinus avellanarius (Zaitseva, 2002, 2008; Zaitseva \& Prydetkevich, 2008).

Museum collections owing to their constant amassment allow establishing a representative sample of rarely recorded species and therefore investigating those aspects of variation and biological features that usually hard to study in the field, especially using methods of live trapping (Zagorodniuk et al., 2014). Dormice are a particularly good example of such species (Bezrodny, 1991) and their age-related variation allows analysing the relation of age groups and the demographic structure of populations (Bieber, 1998; Juškaitis, 1999). As for many other rodents, no clear criteria for age determination based on external characters have been developed for dormice, although detailed schemes were created based on patterns of tooth crown wear (e. g., Homolka, 1979; Klevezal, 2007). The latter makes amassed museum collections especially valuable for studying regional features of rare hibernating species, including the age and sex structure of the forest dormouse samples, particularly from Ukraine.

The aim of this study was to analyse the age-related variation of enamel wear patterns and to develop criteria for age determination based on museum samples. The combination of data on enamel wear and dates of records gives an insight into the seasonal distribution of variants in general and of separate age groups and allows to reveal some details of the species' annual cycle and ecology in Ukraine.

\section{Material and methods}

The study was based on analysis of museum collection samples of the forest dormouse and was led by the idea of amassment of rare faunal data during an extended period from relatively large areas. Since the portion of dormice in trappings of small mammals is less than $0.1 \%$, reliable amount of data cannot be obtained by traditional census methods during a single or even several field research. Zoological collections provide a large amount of data acting as a representative sample collected by many people with different goals in various times and regions (fig. 1). This approach was applied in our former studies as well, e. g., in the analysis of seasonal and perennial changes in abundance of rare mammals in the fauna of Ukraine (Zagorodniuk \& Tkach, 1996; Zagorodniuk \& Godlevska, 2001).

We studied the largest rodent collection in Ukraine, which is deposited in the Department of Zoology of the National Museum of Natural History, NAS of Ukraine, Kyiv (Shevchenko \& Zolotukhina, 2005). Additionally, we analysed the rodent collection of Benedykt Dybowski Zoological Museum at Ivan Franko National University of Lviv (Zatushevskyy et al., 2010). Abbreviations of the names of museums used further in this paper are $\mathrm{NMNH}$ and ZMD, respectively. In total, 101 specimens from Ukraine were included into the analysis.

Metric data including linear body dimensions (L, body length; Ca, tail length; Pl, hind foot length; Au, auricle length; W, weight) and cranial measurements (CBL, condylobasal length; IM3, upper tooth row length; Mand, lower jaw length measured from the condyloid process to the incisor's alveolus) were analysed in MS Excel. Body measurements were taken from specimen labels. Cranial measurements were taken by calliper with $0.1 \mathrm{~mm}$ accuracy. Standard statistics including minimum ( $\mathrm{min})$, maximum (max) and mean (mean) values and standard deviation (SD) were calculated.

The distribution map of specimens (fig. 1) was prepared in QGis 3.10 using Natural Earth public domain layers.

${ }^{1}$ Bairak is a dry gully or ravine covered with broadleaved trees in the zone of steppe and forest steppe (Kotlyakov \& Komarova, 2007). 


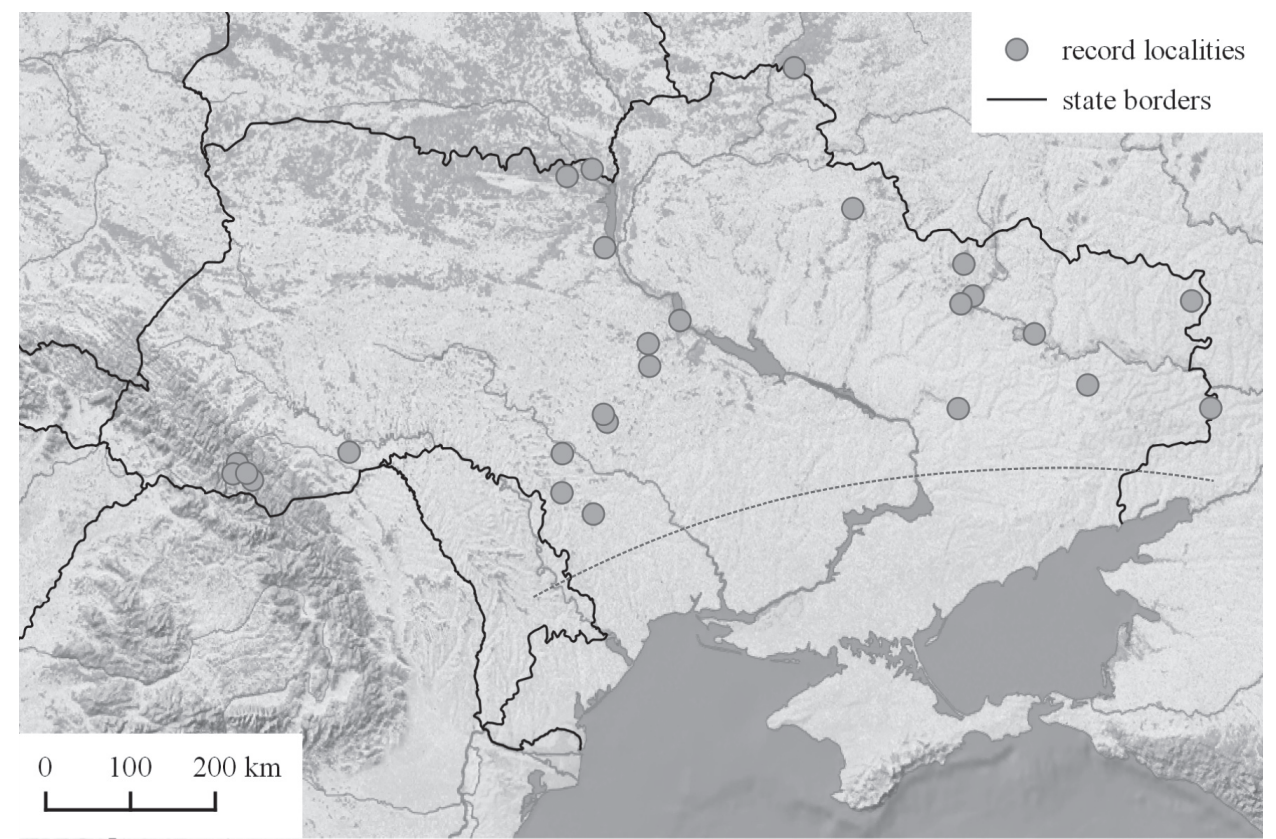

Fig. 1. Geographic details of the studied sample: record localities and the southern boundary of the forest dormouse's distribution.

\section{Results}

General characteristics of the sample based on label data

Among the 101 specimens of the forest dormouse from Ukraine, 96 are deposited in the collection of NMNH, of which only 42 females and 35 males are indicated with the date of record and sex. The portion of males is less by $17 \%$. The distribution of specimens by months is shown in table 1 separately for adults $(n=75)$ and juveniles $(n=10)$. The age ("adults" and "juveniles") in these samples is given according to field determination, i. e. by external features, as indicated on the labels of specimens.

The extreme months of the forest dormouse's records during the year are April and September, although going into and arousal from hibernation are protracted events and the number of specimens recorded in these extreme months is only 8 of 85 , or $9.4 \%$. Based on dates of extreme records, the active period of the species in Ukraine lasts ca. 160 days, or 5.5 months (the extreme dates of records are 15 April 1994 and 24 September 1986). Accordingly, it suggests that hibernation lasts at least 6.5 months.

Table 1. Distribution of forest dormouse specimens from the collection of NMNH by their record date (months) separately for different sex and age as indicated on specimen labels*

\begin{tabular}{c|c|c|c|c|c|c|c|c}
\hline \multirow{2}{*}{ Months } & \multicolumn{4}{c|}{ Adults } & \multicolumn{3}{c|}{ Juveniles } & \multicolumn{3}{c}{ Total } \\
\cline { 2 - 9 } & F ad & M ad & S ad & F juv & M juv & S juv & ad & juv \\
\hline March & - & - & - & - & - & - & 0 & 0 \\
April & 1 & 2 & - & - & - & - & 3 & 0 \\
May & 11 & 5 & 2 & - & - & - & 18 & 0 \\
June & 10 & 9 & 1 & 1 & - & 3 & 20 & 4 \\
July & 7 & 8 & - & 3 & 3 & - & 15 & 6 \\
August & 8 & 5 & 1 & - & - & - & 14 & 0 \\
September & 1 & 3 & 1 & - & - & - & 5 & 0 \\
October & - & - & - & - & - & - & 0 & 0 \\
\hline Total & 38 & 32 & 5 & 4 & 3 & 3 & 75 & 10 \\
\hline
\end{tabular}

${ }^{*} \mathrm{~F}$ - females, $\mathrm{M}$ - males, $\mathrm{S}$ - sex undetermined. 


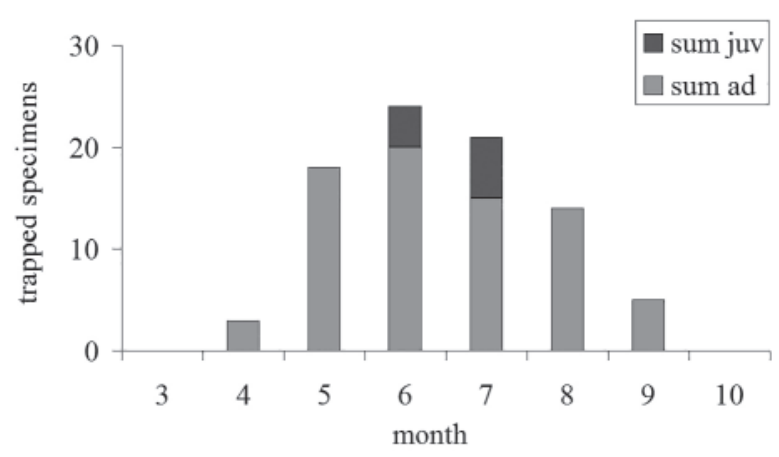

Fig. 2. General dynamics of occurrence of the forest dormouse according to collection data (NMNH and $\mathrm{ZMD})$. Only specimens with correct date of record $(n=85)$ are considered. Data on adults and juveniles are given separately without considering sex. until entering hibernation (in the middle of September) only two months (60-70 days) are available for growth and development (fig. 2). During this short period, juveniles practically reach the size of adults.

\section{Determination of age groups based on tooth crown wear}

Several criteria of age determination in dormice could be applied. In field conditions, age is usually determined according to body dimensions and colouration intensity (young specimens are smaller and dimly coloured) (Klevezal, 2007), although comparison of molar teeth crown wear gives the most accurate results (Lozan, 1961; Homolka, 1979; Klevezal, 2007). We studied the patterns of enamel wear in the forest dormouse and developed an improved scheme for analysis of age-related variation, the idea of which is based on publications cited above.

The scheme includes six gradations, which correspond to standard age groups (table 2), and has a logarithmic scale typical for descriptions of growing processes. The first stages of formation and early stages of enamel wear can be distinguished the most easily allowing to differentiate animals on such stages of individual development as nestling phase, early period of independent living, semi-adulthood before or right after the first wintering, period from breeding to the second wintering. However, older age groups differ

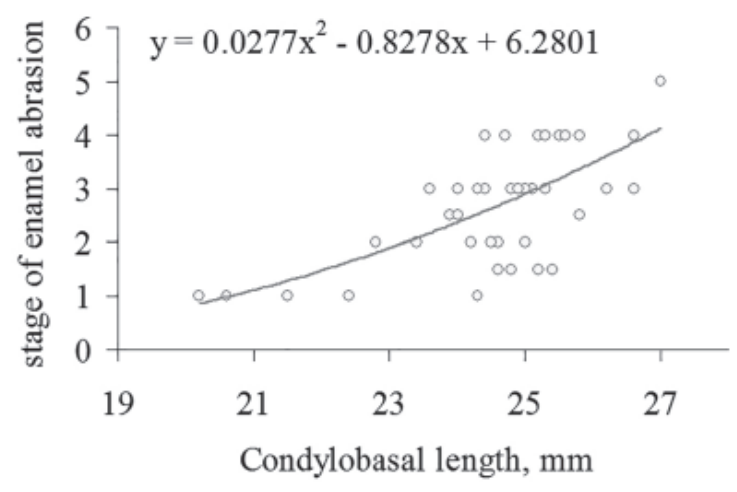

Fig. 3. The skull length of the forest dormouse compared to stages of tooth crown wear. Both features are age-related having no functional but temporal (growth) connection between them. Dormice still grow on the 2 and 3 year of their life as well as the dentine fields on their teeth. Data suggest that specimens collected from different regions in different times probably fed with food of the same rigidity. more dubiously, since the velocity of tooth crown wearing decreases (the area of wearing enlarges greatly) and differences become less noticeable.

When selecting age groups, we considered several key moments. Firstly, we analysed only the upper tooth row, where M1 and M2 turned out to be the most informative teeth. Secondly, attention should be paid mainly to the lingual side of teeth, and particularly to the comparison of abrasion zones, i.e. of dentine bands having several branches, with the outer enamel ridge on the lingual side of teeth.

Metric characters serve as additional criteria, among which we analyse here three, such as the condylobasal length of 
the skull (CBL), full length of the upper tooth row (IM3), and mandibular length (Mand). All three characters, naturally, increase with the age thus somewhat coincide with the corresponding age groups (table 2). In particular, the condylobasal length of the skull, which also increases with the age just as the area of enamel wear, changes from minimum $20 \mathrm{~mm}$ in juveniles to maximum $27 \mathrm{~mm}$ in adults showing a clear connection with the level of tooth crown wear (see fig. 3).

This pattern allows concluding that the growth of craniometrical characters continues in older age groups thus morphometric analysis of populations should be conducted on

Table 2. Stages of enamel wear in different age groups of the forest dormouse (right row, P4 $\rightarrow$ M3)

\begin{tabular}{l|l|l}
\hline $\begin{array}{l}\text { Stage \& age } \\
\text { group }\end{array}$ & Typical morphotype & Description \\
\hline $\begin{array}{l}\text { Stage 1, } \\
\text { before first }\end{array}$ & $\begin{array}{l}\text { JUV: nestlings and 1-2 months } \\
\text { old animals; enamel crests of } \\
\text { wintering }\end{array}$ & $\begin{array}{l}\text { molars are rounded, without } \\
\text { traces of abrasion, M3 often still } \\
\text { (JUV) }\end{array}$ \\
& in the alveolus.
\end{tabular}

Stage $2,<1$ year after wintering (SAD1)

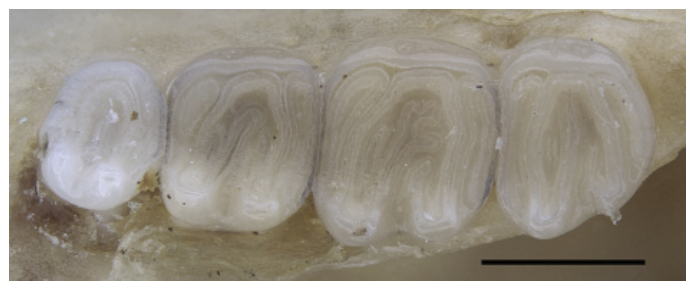

Stage $3, \geq 1$ year old (SAD2)

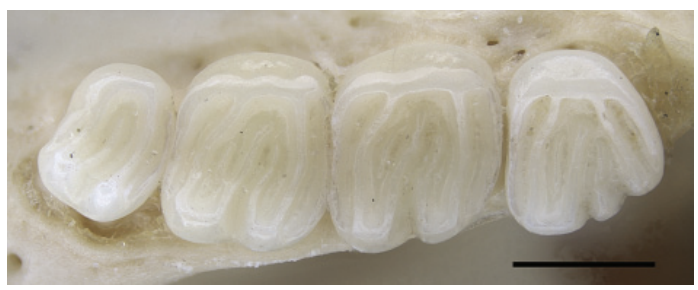

Stage $4, \geq 2$ years old (AD1)

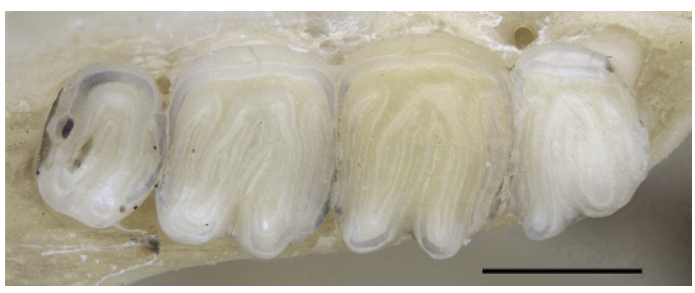

Stage $5, \geq 3$ years old (AD2)

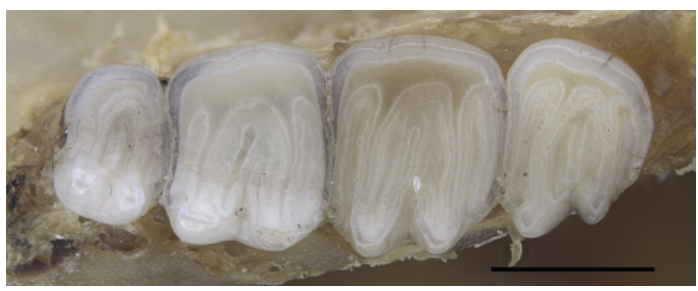

Stage $6, \geq 4$ years old (SEN)

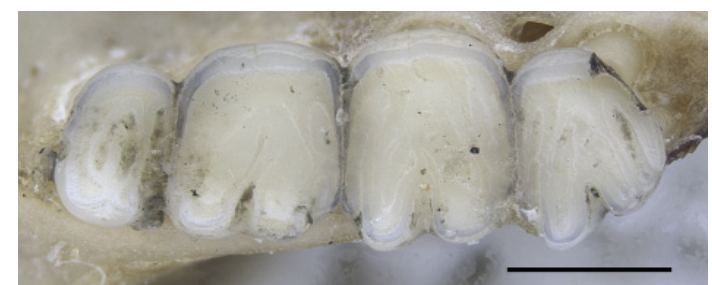

SAD1: less than one-year-old specimens, from autumn to the next spring, enamel crests of molars with separate facets of abrasion, especially on M1 (anterior and lingual edge).

SAD2: one-year-old specimens, the enamel of the ridges have clear and long facets of abrasion on M1 and M2.

AD1: two-years-old specimens, abrasive facets on the enamel of molars are long and wide, especially on M1, less so on M2 and the least so on M3.

AD2: three years old specimens, $\mathrm{P} 4$ and M1 with completely worn enamel facets, on M2 and M3 long bands of dentine, which are already wider than the enamel ridge of the teeth's lingual edge.

SEN: 4 years old and older specimens, the occlusal surface is represented by a complete dentine field surrounded by enamel only along the tooth edge, enamel crests, if present, visible only on M3. 
samples selected by not only craniometrical but several independent criteria. There are many examples when specimens having larger skull size are actually younger as evidenced by the patterns of tooth crown wear.

Dormice of 3 years of age and older (after three wintering) have significantly worn tooth crowns, practically having only stumps of teeth without functional occlusal surface thus they are unable to feed normally. Possibly, it limits their lifespan, although animals of both older age groups (i. e., AD2 and SEN) are already extremely rare by the time of reaching this age.

Dynamics of annual cycle based on enamel wear patterns

The graph in fig. 2 shows a peak of records in June. In this very time, three events take place, such as 1) total records of dormice is the highest, 2) records of adults is the highest, and 3) juveniles appear in the general sample. The dynamics of records of males and females are practically the same, thus sex-related data are combined in the graph. Records of males are distributed in time more evenly: the Pielou evenness index in males is 0.94 against 0.86 in females.

Analysis of the distribution of specimens with consideration of their age according to the criteria of tooth crown wear showed a more detailed picture (table 3 ). The following main features were revealed:

1) age group JUV is the least abundant and represented by fewer specimens than the two following groups SAD1 and SAD2;

2) there is a sharp decline in number in the row of groups AD1, AD2, and SEN, and, practically, if compare each group to the absolute age, we can conclude that the demographic pyramid ends at the age of 4 years;

3 ) individuals of each subsequent age group have a shorter period of activity: dormice of the age group SAD1 appear the earliest (April), followed by groups AD1 and AD2 (May), and then the group SEN appears the latest (June). Autumn activity decreases analogically: groups SAD2 and AD1 are recorded in September, while the latest records of AD2 are dated to July and the group SEN has only a single record in July (see table 3). Such pattern of annual distribution suggests a more rapid metabolism in younger specimens: most of the energy is spent for growth, development, and reproduction instead of deposition, so there is a need for a longer period of activity.

Besides, the low portion of younger age groups, which contrasts to a normal population pyramid, could be related to the high sensibility of the method of determination of younger age groups based on the level of enamel wear. Therefore, older age groups cannot be strictly associated with the absolute (calendar) age of specimens, as it was considered earlier (e. g., AD2 is not strictly equal to 3 years of age, but may include specimens of 2 to 4 years of age). This is due to the complexity of differentiation of stages of enamel wear in older age

Table 3. Temporal distribution (by months) of forest dormouse specimens of different age groups selected according to enamel wear patterns

\begin{tabular}{l|c|c|c|c|c|c|c}
\hline \multicolumn{1}{c}{ Months } & JUV & SAD1 & SAD2 & AD1 & AD2 & SEN & Total \\
\hline March & - & - & - & - & - & - & 0 \\
April & - & 1 & - & - & - & - & 1 \\
May & - & - & 3 & 6 & 2 & - & 11 \\
June & 1 & 1 & 1 & 3 & 3 & 1 & 10 \\
July & 4 & - & - & 4 & 4 & - & 12 \\
August & 2 & 3 & 3 & 1 & 1 & - & 10 \\
September & - & - & 1 & 1 & - & - & 2 \\
October & - & - & - & - & - & - & 0 \\
\hline Total & 7 & 5 & 8 & 15 & 10 & 1 & 46 \\
\hline
\end{tabular}


Table 4. Standard morphometric characters of the forest dormouse - juveniles (before the first hibernation, i.e. JUV and SAD1) and adults (after at least one hibernation, i. e. SAD2 to SEN)

\begin{tabular}{|c|c|c|c|c|c|c|c|c|c|}
\hline \multirow[t]{2}{*}{ Age } & \multirow[t]{2}{*}{$\begin{array}{c}\text { Sta- } \\
\text { tistics }\end{array}$} & \multicolumn{5}{|c|}{ Body measurements } & \multicolumn{3}{|c|}{ Cranial measurements } \\
\hline & & $\mathrm{L}$ & $\mathrm{Ca}$ & $\mathrm{Pl}$ & $\mathrm{Au}$ & $\mathrm{W}$ & $\mathrm{CBL}$ & IM3 & Mand \\
\hline \multirow[t]{5}{*}{ Juveniles } & $\min$ & 66.0 & 67.0 & 18.0 & 6.0 & 13.5 & 20.2 & 9.8 & 11.4 \\
\hline & $\max$ & 96.1 & 94.4 & 21.8 & 15.0 & 31.2 & 25.4 & 12.4 & 14.8 \\
\hline & mean & 81.1 & 75.0 & 19.7 & 11.2 & 22.4 & 22.8 & 11.1 & 13.0 \\
\hline & SD & 8.72 & 7.43 & 1.14 & 3.07 & 12.5 & 2.01 & 0.91 & 1.29 \\
\hline & $\mathrm{n}$ & 18 & 18 & 18 & 17 & 2 & 8 & 9 & 8 \\
\hline \multirow[t]{5}{*}{ Adults } & $\min$ & 79.5 & 63.5 & 18.7 & 10.0 & 19.4 & 23.4 & 11.0 & 12.8 \\
\hline & $\max$ & 119.0 & 103.0 & 23.0 & 16.0 & 39.5 & 26.6 & 12.7 & 15.8 \\
\hline & mean & 94.8 & 83.7 & 20.6 & 13.2 & 29.2 & 24.9 & 11.8 & 14.4 \\
\hline & SD & 8.07 & 7.41 & 0.94 & 1.33 & 5.55 & 0.78 & 0.41 & 0.62 \\
\hline & $\mathrm{n}$ & 48 & 41 & 47 & 47 & 23 & 33 & 34 & 32 \\
\hline
\end{tabular}

groups: the more the enamel is worn the more invisible become age-related differences. The developed by us method of age group differentiation allows to clearly separate phases of the life cycle of animals of at least 1 years of age. Particularly, considering the date of record we can distinguish juveniles before and after their first hibernation just as subadults before and after their second hibernation.

The very low number of animals of the age groups JUV and SAD1, i.e. individuals with incompletely developed tooth row (practically, dormice that just left the nest) and dormice with minimal enamel wear (before or right after wintering) is the most surprising. When analysing the demographic structure of the sample, the group SAD1, obviously, chronologically should be merged with the group JUV. However, it would distort the picture of life cycle dynamics (see table 3) "blurring" the time of appearance of juveniles in the sample. Therefore, considering the phases of life cycle and related periods of enamel wear, the group SAD1 should be united with the group SAD2. However, it does not solve the issue of low number of specimens in the group SAD2. The hypothesis that would explain this issue is presented in the Discussion.

Records of juveniles that can be identified by external characters are absent already in August (see fig. 2), which suggests their rapid growth and disappearance of juvenile traits (small size, dim colouration). The fading of juveniles leads to the alignment of the sample by external characters. The growth of juveniles is quite quick and, by the time of wintering, they cannot be distinguished from the adults according to metric parameters. However, the general sample consisting of individuals that already led an independent life (i. e., those that can be trapped) but still growing is characterised by smaller body weight and dimensions (table 4).

The velocity of increase of external dimensions with the age is high. Only one-year-old specimens (from birth to entering hibernation) differ by clearly smaller body size, and they are well distinguished in the general sample (fig. 4). The same applies to cranial dimensions (see fig. 3).

\section{Discussion}

Data on "normal" life cycle are important for detecting possible changes in seasonal activity of dormice in the context of climate warming and decrease of winter hibernating period. Hibernation is clearly a facultative character of the family Gliridae, the geographic distribution 


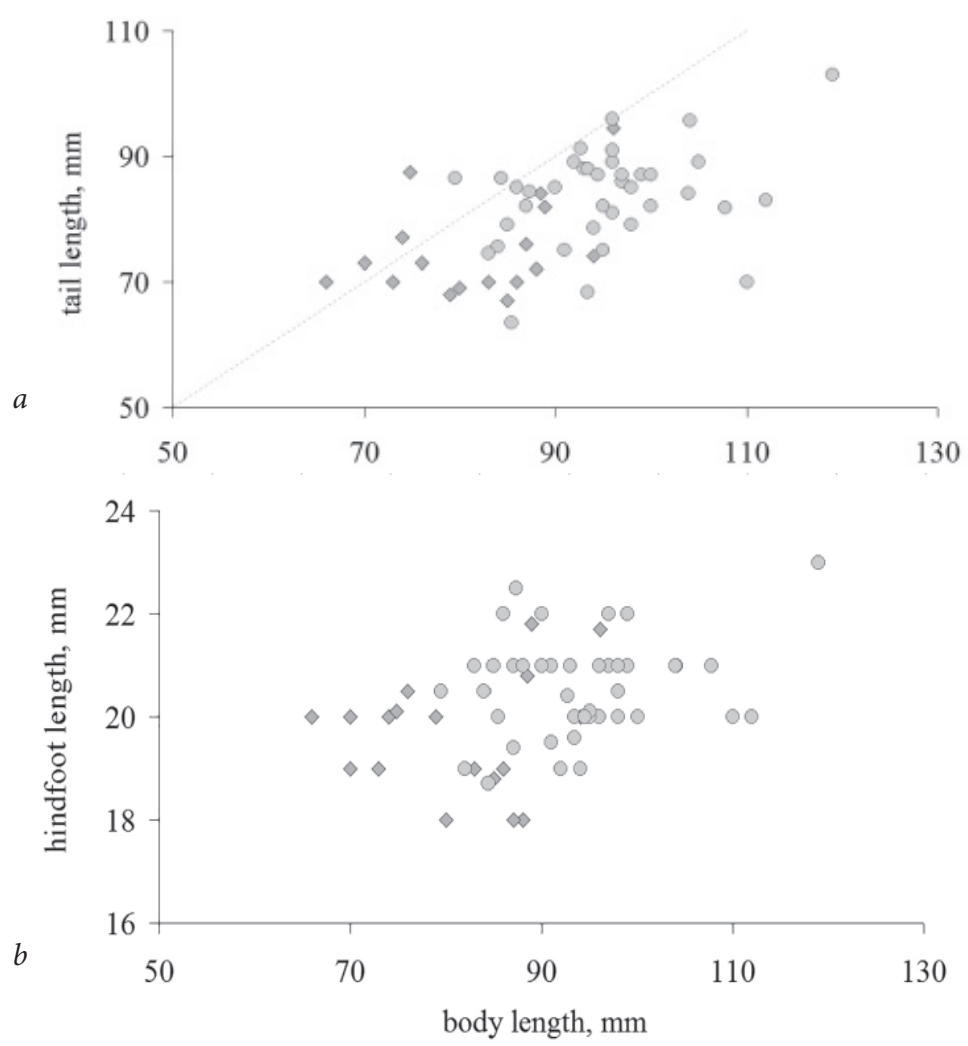

Fig. 4. Changes in the length of the tail ( $a$ ) and hind foot $(b)$ compared to the body length in juvenile (grey rhombi) and adult (orange circles) dormice. Samples are the same as in table 4.

proposed objects, the dormouse most gladly consumed mealworms, grasshoppers, locusts, and nocturnal butterflies. At the same time, the animal refused eating grains, walnuts, honey, eggs, etc. However, in autumn the dormouse ate only the latter kind of food and quickly gained weight (fig. 5). The same was observed regularly in Novo-Illienko Biological Station, which is located in the floodplain of the Derkul River, where dormice were observed preying on insects without causing noticeable damage to fruit and berry plants, and their excrements were full of chitin. Similar patterns of the predominance of animals in the summer diet of dormice and the change of diet in autumn were revealed in other parts of the species' range as well (Paolucci et al., 1987; Nowakowski \& Godlewska, 2006; Juškaitis \& Baltrūnaite, 2013).

In autumn, we regularly trapped dormice on trap-lines where the European crab apple was growing nearby. Almost under each apple tree, 2-3 dormice were trapped (according to data from Kondratenko \& Zagorodniuk, 2006 with additions). Since apple trees in the forest steppe and steppe zones play the role of consorts, we suggest that dormice are attracted not so much by the apples but by the large number of both free living and fruit consuming insects especially abundant in early autumn. Besides, hollows in the trunks and at the base of the apple trees can serve as shelter for hibernation.

Biological features of young dormice can explain the abovementioned low number of juveniles in the general sample (the lowest compared to other age groups). Firstly, juveniles leave the nests in the first half of July and therefore can be trapped only during two months before they enter hibernation. Secondly, the switch in diet from insects to high-calorie food occurs closer to hibernation, approximately in the middle of August. Since such highcalorie lures are traditionally used in traps (Berzodny, 1990, pers. comm.), juveniles can be caught on trap-lines only after they changed their diet, i. e. from mid-August. 

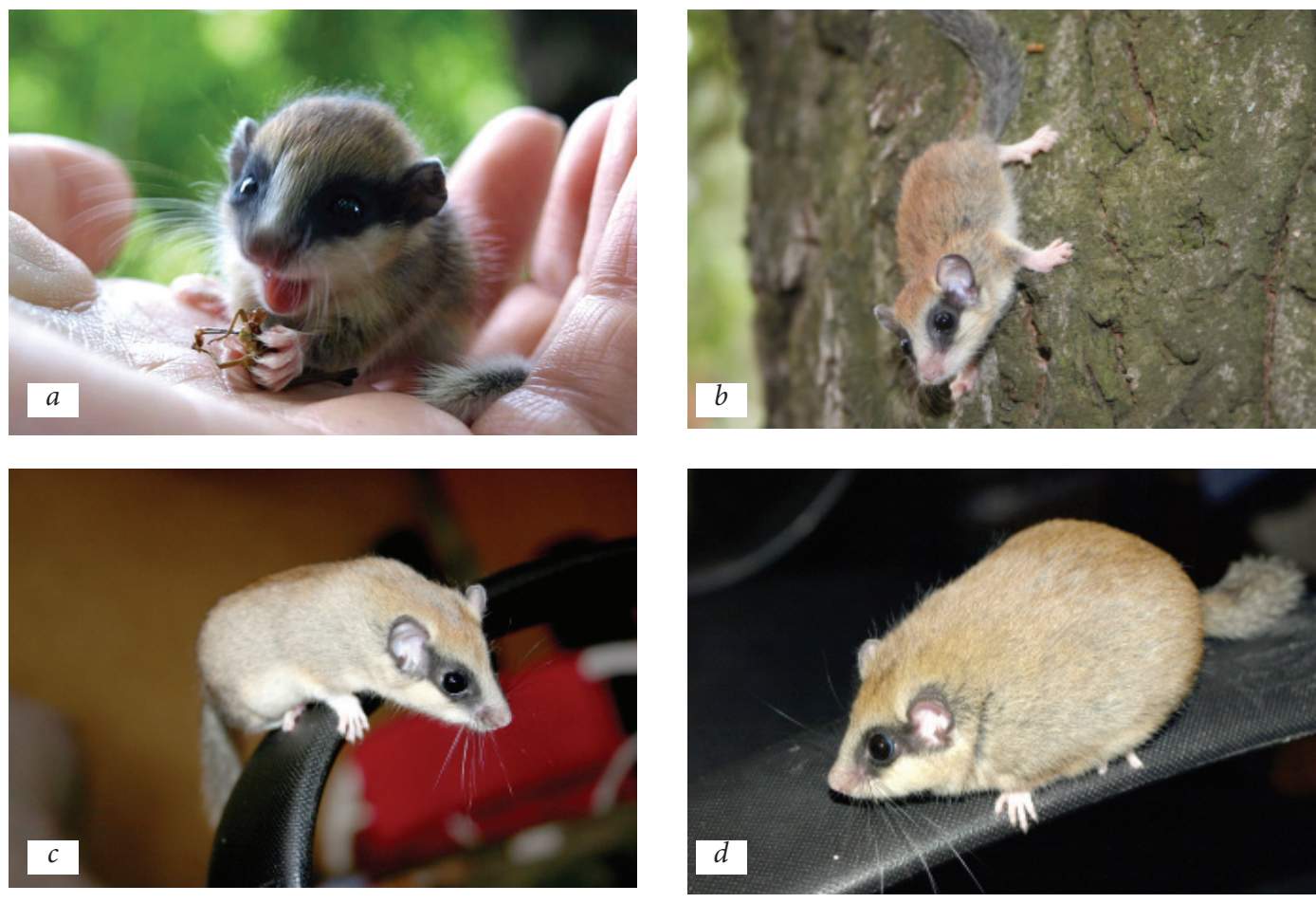

Fig. 5. Changes in the external appearance of the forest dormouse during the first year of life. The animal was caught in early June 2009 near Luhansk: $a-19$ of June, $1-2$ weeks old, feeding exclusively with insects, mainly locusts; $b-16$ of July, $1+$ month of age, active motions, feeding with insects, including locusts, butterflies, and mealworms; $c-18$ of August, 2+ months of age, low mobility, willingly feeding with mealworms, also began to consume nuts, honey, and cookies; $d-16$ of September, $3+$ months of age, low mobility, feeding almost exclusively with nuts, honey and other energy-rich products instead of insects, which became less preferred.

Thus, the study of museum collections showed the possibility of studying age-related patterns of enamel wear in the forest dormouse, a species with complex annual cycle. The obtained results allowed not only to develop criteria for age group differentiation but also to reveal little known specifics of the species' biology, in particular those that are hard or impossible to study in field conditions. This may be due to the complexity of such observations, infrequent occurrence of the animal in trappings or without causing damage to the animal in case of live trapping. Museum collections represent a large base of amassed data available for analysis of "recording structures" that provide information on ontogenetic age, etc. A combination of such data with trapping dates in case of animals with complex life cycles allows obtaining new knowledge on the age-sex structure of samples and its changes in time, in particular in the forest dormouse from the Ukrainian part of the species range.

We are greatly thankful to E. Ulyura, head of the mammal collection of NMNH for her kind help in processing collection materials and to A. Zatushevskyy (mammal collection of the Zoological Museum of Lviv University) for facilitating our research. We are grateful to O. Martynov for helping to take the pictures of teeth. The database on trappings of the forest dormouse was created together with O. Kondratenko. We further acknowledge V. Parkhomenko for the improvement of photos, and O. Kovalchuk for proofreading the manuscript.

\section{References}

Bieber, C. 1998. Population dynamics, sexual activity, and reproduction failure in the fat dormouse (Myoxus glis). Journal of Zoology, London, 244, 223-229.

Bezrodny, S. I. 1990. On methods of dormice trapping. Vestnik Zoologii, 24 (4), 84-85 [In Russian].

Bezrodny, S. V. 1991. The distribution of the Gliridae (Rodentia) in Ukraine. Vestnik Zoologii, 25 (3), 45-50 [In Russian]. 
Godlevska, L. V., Gol'din, P. E. 2014. Unusual age structure of the winter aggregation of Nyctalus noctula (Chiroptera) in Kyiv. Vestnik Zoologii, 48 (6), 533-538.

Homolka, M. 1979. Zur Alterbestimmung der Schläfer (Gliridae). Folia Zoologica, 28 (2), 103-114.

Juškaitis, R. 1999. Demographic structure of two common dormouse (Muscardinus avellanarius L.) populations in Lithuania. Proceedings of the Latvian Academy of Sciences. Section B, 53, No. 2 (601), 107-111.

Juškaitis, R. \& Baltrūnaité, L. 2013. Seasonal variability in the diet of the forest dormouse, Dryomys nitedula, on the north-western edge of its distributional range. Folia Zoologica, 62 (4), 311-318. https://doi. org/10.25225/fozo.v62.i4.a9.2013.

Kalabukhov, N. I. 1956. The Hibernation of Animals. Kharkiv University Press, Kharkiv, 1-267 [In Russian].

Klevezal, G. A. 2007. Principles and Methods of Age Determination of Mammals. KMK Scientific Press, Moscow, 1-282 [In Russian].

Kondratenko, O., Zagorodniuk, I. 2006. Small mammal's fauna of reserved territories of Eastern Ukraine based on results of census using traps and pitfalls. Proceedings of the Theriological School, 7, 120-135 [In Ukrainian].

Kotlyakov, V. M., Komarova, A. I. 2007. Elsevier's Dictionary of Geography: in English, Russian, French, Spanish and German. Elsevier, 1-1072.

Kryštufek, B., Vohralik, V. 1994. Distribution of the forest dormouse Dryomys nitedula (Pallas, 1779) (Rodentia, Myoxidae) in Europe. Mammal Review, 24 (4), 161-177. https://doi.org/10.1111/j.1365-2907.1994. tb00140.x

Lebid, Ye. O., Knysh, M. P. 1998. Predation of the forest dormouse (Dryomys nitedula Pall.) on small hollownesting birds. In: Buhayenko, V. V., ed. Vakalivshchyna: collection of scientific works. Sumy Pedagogical Institute, Sumy, 149-153 [In Ukrainian].

Lozan, M. N. 1961. Determination of the age of the forest dormouse (Dryomis nitedula Pall.) and hazel dormouse (Muscardinus avellanarius L.). Zoologichesky Zhurnal, 40 (11), 1740-1742 [In Russian].

Lozan, M. N., Belik, L. I., Samarskii, S. L. 1990. Dormouse (Gliridae) of the South-west of the USSR. Moldova State University, Shtiintsa, Chişinău, 1-146 [In Russian].

Nowakowski, W. K., Godlewska, M. 2006. The importance of animal food for Dryomys nitedula (Pallas) and Glis glis (L.) in Białowieża forest (East Poland): analysis of faeces. Polish Journal of Ecology, 54 (3), 359-367.

Paolucci, P., Battisti, A., De Battisti, R. 1987. The forest dormouse (Dryomys nitedula Pallas, 1779) in the Eastern Alps (Rodentia Gliridae). Biogeographia, 13, 855-866. https://doi.org/10.21426/B613110340.

Shevchenko, L. S., Zolotukhina, S. I. 2005. Mammals. Issue 2. Insectivores, Bats, Lagomorphs (Catalogue of Collections). National Museum of Natural History NAS of Ukraine, Kyiv, 1-238 [In Russian].

Sokur, I. T. 1960. Mammals of the Fauna of Ukraine and Their Economic Value. Derzhuchpedvydav, Kyiv, 1-211 [In Ukrainian].

Zagorodniuk, I. V., Tkach, V. V. 1996. The present state of fauna and the historical changes of abundance of bats (Chiroptera) in the territory of Ukraine. Reports of the National Academy of Sciences of Ukraine, 5, 136-142 [In Ukrainian].

Zagorodniuk, I., Godlewska, L. 2001. Bats in the collections of zoological museums of Ukraine: review and phenological analysis of data. In: Zagorodniuk, I., ed. Migration Status of Bats in Ukraine. Kyiv, 122-156. (Novitates Theriologicae; Pars 6) [In Ukrainian].

Zagorodniuk, I. 2008. Mammal diversity and species richness of guilds. Scientific Bulletin of Uzhgorod University. Series Biology, 24, 11-23 [In Ukrainian].

Zagorodniuk, I. V., Emelyanov, I. G. 2012. Taxonomy and nomenclature of mammals of Ukraine. Proceedings of the National Museum of Natural History, 10, 5-30 [In Ukrainian].

Zagorodniuk, I., Emelyanov, I., Chervonenko, O. 2014. Zoological collections and museums as centres of biodiversity investigations. In: Zagorodniuk, I., ed. Zoological Collections and Museums. National Museum of Natural History NAS of Ukraine, Kyiv, 6-9 [In Ukrainian].

Zaitseva, A. 2002. Number and seasonal dynamics of dormice species (Myoxidae) of Podillya. Visnyk of Lviv Univ. Biology Series, 30, 65-69 [In Ukrainian].

Zaitseva, G. Y. 2008. Monitoring of population of the common dormouse (Muscardinus avellanarius L.): annual and seasonal nest-building dynamics on the territory of Kamianetske Pridnistrovia. Newsletter of the Precarpathian National University named after Vasyl Stefanyk. Series Biology, 12, 71-75 [In Ukrainian].

Zaitseva, H., Prydetkevich, S. 2008. Dynamics of occupancy of nest-boxes by arboreal animals at the territory of Kamenetske Pridnistrovja. Proceedings of the Theriological School, 9, 157-164 [In Ukrainian].

Zaitseva, G. Yu., Sagaidak, A. V. 2011. Dynamics of nesting activity and biocoenotic relations of dendrophile rodents on the territory of Mizhrichynsky Regional Landscape Park (Chernihiv region). Scientific Herald of NULES of Ukraine. Series Forestry and Decorative Gardening, 164 (3), 97-104 [In Ukrainian].

Zatushevskyy, A. T., Shydlovskyy, I. V., Zakala, O. S., Dykyy, I. V., Holovachov, O. V., Senyk, M. A., Romanova, Kh. J. 2010. Catalogue of the Mammals Collection of the Zoological Museum of Ivan Franko National University of Lviv. Lviv University Press, Lviv, 1-442 [In Ukrainian].

Received 14 December 2019

Accepted 25 February 2020 